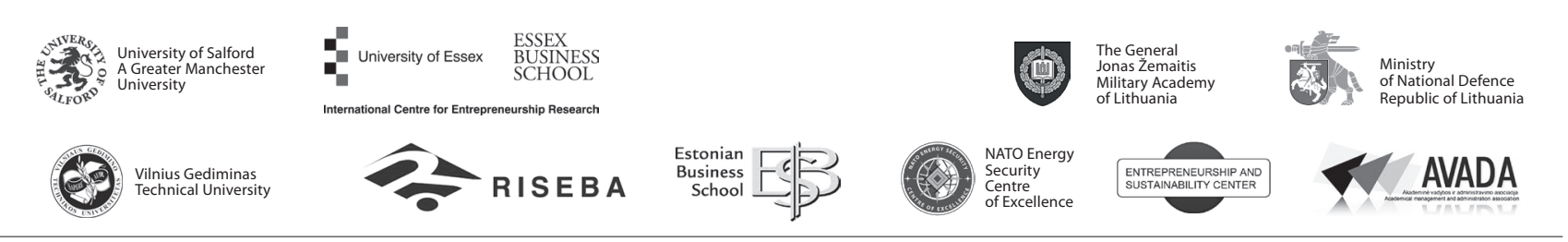

JOURNAL OF SECURITY AND SUSTAINABILITY ISSUES

ISSN 2029-7017 print/ISSN 2029-7025 online

2018 September Volume 8 Number 1

https://doi.org/10.9770/jssi.2018.8.1(1)

\title{
PROFILE OF A LONE WOLF TERRORIST: A CRISIS MANAGEMENT PERSPECTIVE
}

\author{
Tomáš Zeman', Jan Břeň², Rudolf Urban ${ }^{3}$ \\ 1,2 University of Defence in Brno, Faculty of Military Leadership, \\ Department of Emergency Management, Brno, Czech Republic \\ ${ }^{3}$ The Police Academy of the Czech Republic in Prague, Faculty of Security Management, \\ Department of Management and Informatics
}

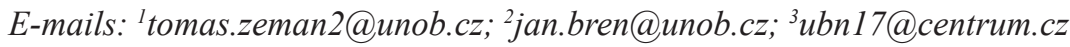

Received 10 December 2017; accepted 25 May 2018

\begin{abstract}
This paper focuses on terrorist attacks carried out by so-called 'lone wolves' or 'lone actors'. It provides an analytical evaluation of the basic characteristics of these attackers and discusses possible access to their identification in society. To create the profile of a 'typical' lone wolf, we collected information from a database of lone wolves who committed their terrorist attacks in the United States, Canada, the European Union, Switzerland, Norway and Australia from 1998 to 2016. Based on these data, it was demonstrated that lone wolves are not homogenous group, therefore, there is no one 'typical' lone wolf. Instead, three main groups of lone wolves were identified: 1) lone wolves with a criminal past, 2) lone wolves with a mental illness and 3) young lone wolves coming from minority groups in the country. These characteristics could be used as an auxiliary tool by state security forces during identification of potential lone wolf terrorists.
\end{abstract}

Keywords: terrorism; lone wolf; crisis management; profile; identification

Reference to this paper should be made as follows: Zeman, T.; Břeň, J.; Urban, R. 2018. Profile of a lone wolf terrorist: a crisis management perspective, Journal of Security and Sustainability Issues 8(1): 5-18. https://doi.org/10.9770/jssi.2018.8.1(1)

JEL Classifications: F01, F02

\section{Introduction}

Terrorism constitutes one of the most serious problems of the current security environment and its management. Identifying the roots of terrorist activities is one of the decisive factors of preparedness of security systems for individual states (e.g. Lietuvnikè et al. 2018; Kuril 2018; Todorov et al. 2018; Lincényi 2017; Šišulák 2017). Early predictions and measures are important aspects in the fight against terrorism. Adequate security system preparedness to terrorist threats requires an analysis of relevant information that could consequently be used during the formation and implementation of the anti-terrorism policies of a state. Within the phenomenon of terrorism as a method of using force or threats of violence, carried out by individuals, groups of individuals or state-supported actors, it is possible to follow two lines of development: terrorism organized by terrorist groups and terrorism performed by individuals acting independently. This paper focuses on the latter one - terrorist acts carried out by 'lone wolves' or 'lone actors', as a specific threat to contemporary society.

In publications and databases (e.g. Ellis et al., 2016; Hamm and Spaaij, 2015; Spaaij, 2010), we can find several definitions characterizing the term lone wolf in the field of terrorism. For example, Hamm and Spaaij (2015) see a lone wolf quite strictly as an individual who: 1) acts alone; 2) does not belong to a terrorist group 
or network; 3) acts without influence of a leader; 4) directs his tactics and methods by himself. On the other hand, Ellis et al. (2016) used for their CLAT database a wider definition, when they admitted that lone actor(s) may be an individual, dyad or triad, whose decision to act is not directed by any group or other individuals, and they are neither directly supported by them in the planning, preparation and execution of the attack. In contrast to the narrow definition of Hamm and Spaaij (2015), the wider definition of Ellis et al. (2016) allows a lone wolf to be a member of terrorist or extremist groups, if he carries the terrorist attack independently of that group. However, there is consensus that a lone wolf performs his terrorist attacks without direct influence and support from any terrorist group or other individuals. This implies that lone wolves act on their own, and it is very difficult to identify their objectives, intentions and methods for carrying out their attacks. Although some lone wolves have links to extremist or terrorist groups, the majority of them do not have any such connections (Ellis and Pantucci, 2016a). In the case of lone wolves, it is not possible to infiltrate any structures or converge purposefully. Such procedures cannot be applied in this category of attackers at all. This approach increases the effectiveness of the impact of their attacks and reduces the possibility of prediction and prevention against them. Therefore, lone wolves constitute a serious challenge for an existing security system for the protection of the population.

Many recent studies highlighted a tendency for lone wolfs to be loners (Gill et al., 2014; Gruenewald et al., 2013; McCauley and Moskalenko, 2014; Spaaij, 2012). On the other hand, in other studies (e.g. Ellis et al., 2016), it was suggested that lone wolves are not necessarily completely socially isolated, as it has been previously assumed. Ellis et al. reported that only $28 \%$ of lone wolves recorded in the European CLAT database were socially isolated, while $46 \%$ of lone wolves somehow signaled their intentions or extremist attitudes to others, usually to their friends or family members before they actually committed a terrorist act. Nowadays, however, expressing views on the Internet is of the same significance. Based on these results, Ellis et al. suggested that teaching the public to recognize the extremist behavior in people in their surroundings and give them the opportunity to report this behavior is an important tool in the possible tactics how to fight against lone wolves. On the other hand, some lone wolves are well aware of their weaknesses of this kind, e.g. Anders Breivik, probably the most successful terrorist in this field. He wrote in his manifesto:

"You will increase your chance of being apprehended by 100\% for every person you involve. Do not trust anyone unless you absolutely need it (which should never be the case). Do absolutely everything yourself (Berwick, 2011, p. 853)."

Autonomy in preparation of terrorist acts is in our opinion the most suitable characteristic of lone wolfs. However, this does not mean that they do not communicate with others. Moskalenko and McCauley (2011, p. 124) suggested that a lone wolf is actually dependent on others in some way: "The lone-wolf terrorist depends on others for ideas, if not for action."

The analyses of the current existing capabilities of intelligence services indicate that there is no effective method or possibility of an effective way of warfare with lone wolves. Within security management, governments could allocate financial resources to intelligence services to increase the number of employees and adopt new intelligence technology, but in the case of lone wolves, these measures do not have to be sufficiently effective. Nowadays, there are numerous means for tracking suspects and their activities (wiretapping, CCTV systems, GPS locators, monitoring PC, etc.). A prerequisite for the successful use of these resources, however, is a previous identification of suspects. The idea of continuous mass surveillance over a number of years, before someone showed any aggressive tendencies, is almost unreal. Moreover, the fact that the attack may come from a person who has never fallen under slightest suspicion speaks against this procedure. In accordance with the above-mentioned assumption, it is desirable to identify and define the basic characteristics or indicators of the behavior of possible lone wolves. The complexity is hidden in the principle of comprehensive understanding of their thinking, actions and intentions. 


\section{Possibilities of lone wolves identification}

In this paper, the theoretical model of terrorism by Kemmesies (2006) was used for the selection and grouping of traits that could be useful in the process for identification of a lone wolf terrorist. Kemmesies proposed three main factors generating a terrorist. The first factor is the personality of a potential terrorist, which includes traits such as psychical dispositions, life values, knowledge or skills. These traits are adopted by an individual during the process of socialization. This individual level determines the perceptions and interpretation of reality by the individual. The second factor delimited by Kemmesies is ideology. Extremist or terrorist ideology is equally important in the process of terrorist shaping since it plays a key role in justifying the violence. The third factor according to Kemmesies is the environment surrounding the potential terrorist. This environment includes different social structures from the structures of which the potential terrorist is a direct part and directly influence his personality such as family, school or circle of friends, through social structures that affect the individual without actually belonging to them, for example, media, governmental institutions, state security forces or the labor market, to superior social structures such as cultural patterns and values or a shared interpretation of history.

The first indicator that can be used for identification of a lone wolf terrorist is a factor of an individual level. At this level, the emphasis is on the psychological characteristics of the individual. An individual level can be very important for distinguishing lone wolves from radicals with no violent intentions, e.g. Khalil (2014) argues that individual-level stimuli such as vengeance, status or yearning for adventure are often a true cause that leads individuals to engage in terrorist activities. Moskalenko and McCauley (2011) suggested that group identification with some victims could be a psychological state, which allows lone wolves to sacrifice themselves for a common cause.

There has been long discussion about the extent to which terrorists tend to have mental health issues. Plenty of psychological theories of terrorism emerged, especially up to the 1980s. These theories were exhaustively and critically reviewed by Victoroff in 2005 (Victoroff, 2005). His criticism pointed in particular to the fact that these theories were based mostly on speculations, whereas well-established controlled empirical studies were rare. He also argued that there is no such a thing as a "mind of the terrorist". There are many types or terrorists with different origins, socioeconomic status, motivation, ideology etc. However, it is assumed by some authors (e.g. Bakker and de Graaf, 2010; McCauley and Moskalenko, 2008), that lone wolves could be just the type of terrorists with a high likelihood to suffer some kind of mental disturbances. A few empirical studies (e.g. Corner et al., 2016; Corner and Gill, 2015; Gruenewald et al., 2013; Spaaij, 2010) support this opinion. Especially interesting is the finding of Gruenewald et al. (2013), who observed a statistically significantly higher frequency of mental illnesses in lone wolf far-right extremists compared to other far-right extremists. Corner et al. (2016) came to a similar conclusion when the prevalence of mental illness was analyzed in mass casualty offenders, lone-actors, solo-actors, lone-dyad and group-actor. They discovered that the highest prevalence of mental illness was found in mass casualty offenders, and lone actors, meanwhile the lowest prevalence of mental illness was found in group-actors. They explained this effect by the fact, that "terrorist groups are selective in who they recruit", while mental illness is definitely not an indicator for a suitable recruit. On the other hand, this selection effect is completely absent in lone wolf terrorists. Corner and Gill (2015) as well as Corner et al. (2016), noticed the fact that many previous studies work only with information whether a given terrorist suffered from a mental illness without accurate clinical diagnosis of the disease. Corner et al. (2016) compared the rate of prevalence of individual mental disease according ICD-10 (World Health Organization, 2010) criteria between lone-actors, group-actors and the general population. In only three illnesses, they reported a significantly higher prevalence among lone-actors compared to the other groups. This effect was mostly pronounced in schizophrenia; whose prevalence among lone-actors exceeded $8 \%$ compared to around $1 \%$ prevalence in the general population.

The second factor is the ideology pursued by the individual. As noted by Pantucci et al. (2015, p. 5), "the phenomenon of lone-actor attacks is not restricted to specific ideology". Nevertheless, they see three main ideological drivers: 1) right-wing ideas; 2) radical Islamist ideology and 3) self-developed ideology. Commonly, the lone wolves terrorism phenomenon closely relates to a 'leaderless resistance' strategy. Joosse (2017) sees leaderless resistance as the ideology that motivates lone wolf terrorism. As was previously mentioned, lone 
wolves act on their own. Despite this statement, such persons may sympathize with some terrorist organizations, although they may not be members of them. This fondness strengthens the position, commitment and intentions of the lone wolf in their future actions.

The radical ideology of some lone wolves could be used against them under certain circumstances. As reported by Ellis and Pantucci (2016b), 46 \% of lone wolf terrorists in CLAT database indicate in some way their intention to commit terrorist attacks. Moreover, $34 \%$ of lone wolves exhibited changed behavior before the attacks, such as "loss of interest in other friends and other activities not associated with extremist ideology, groups or causes" (Ellis and Pantucci, 2016b, p. 3), which could be indicated by their surroundings. This fact led Ellis and Pantucci (2016b) to highlight the significance of public awareness and their willingness to cooperate with authorities for timely detection of lone wolves. They recommended to ensure programs aimed at increasing public awareness of terrorist threat and the identification of warning signals in their surroundings. They also emphasized the need for cooperation with social media companies, which may facilitate the identification of potential lone wolves on the internet.

The final indicator that can potentially be used for lone wolf identification is the environmental factor. It is not sufficient to examine only the current social situation of the person. An important aspect is the family environment and the upbringing process. Gill et al. (2014) noticed that in their database of lone wolves in the US and Europe, only a quarter was married (24.5\%), which is relatively low compared to organized terrorists. In addition, Gill et al. took notice of the fact that despite relatively high educational achievement, the occupation of lone wolves does not often match their education. $40.2 \%$ of lone wolves were unemployed, $9.8 \%$ student and $23.2 \%$ worked in service industry. As indicated by Gill et al., this distribution is diametrically different from the situation of organized terrorists who usually have a job. Regarding the criminal activities of lone wolves, $41.2 \%$ had previous criminal convictions. $63.3 \%$ of those with convictions had been in jail and $32.3 \%$ of those who were incarcerated had adopted the ideology during jail time. Gill et al. also reported that $37.8 \%$ of lone wolves had previously engaged in violent behavior and $22.7 \%$ had a history of substance abuse.

Apart from the described factors of a lone wolf personality, other important input aspects are the process of radicalizing an individual and communicating his ideas with the external environment. Actually, the process of radicalization is sort of an intersection as well as extension of the aforementioned factors. This process requires exchanging ideas with other people in some form, e.g. direct communication with other people, internet etc. Communication of ideas with other people is usually the cause and effect of lone wolf radicalization at the same time. Signs of radical actions and attempts to impose their ideas on the public can be primary indicators for detecting potential terrorist activities in the future. However, many authors (e.g. Holt et al., 2015; Khalil, 2014; Schuurman and Eijkman, 2015) point out the fact that a radical attitude and extreme actions are not the same. There are many individuals with extreme opinions, but only a slight fraction of them ever take measures to perform a terrorist attack. On the other hand, there are many terrorists, who do not share extreme opinions. Khalil (2014) argues that whereas supportive attitudes for political violence is driven mainly by collective causes, e.g. repression, socioeconomic inequality etc.; contribution to political violence is often caused by individual-level motives. If this were true, what impact does the radicalization of a person actually have on the likelihood of him performing a terrorist act?

Ellis et al. (2016) pointed to the fact that a part of the observed increase in the number of terrorist acts could be attributed to the expansion of the Internet. According to recent statistics, the internet is becoming the most common platform for terrorists to show their conviction and intentions (Zeman et al., 2017). Hamm and Spaaij (2015) bring into focus the significance of the Internet in the mechanism of radicalization in lone wolves in the US. The authors noticed that prior to September 11, 2001 radicalization of lone wolves was associated mostly with their previous membership in an extremist group; since September 11, 2001 the source of radicalization has been gradually replaced by the Internet, online social networks, etc.

The aim of our research was to characterize the profile of a lone wolf terrorist based on the data of lone wolves who have committed their attacks in the United States, Canada, the European Union, Switzerland, Norway and Australia from 1998 to 2016. 


\section{Methods}

In the first step, we created a Lone Wolves Database (LWD), which contains the cases of lone wolves committing their terrorist attacks in the United States, Canada, the European Union, Switzerland, Norway and Australia from 1998 to 2016. We utilized the Global Terrorist Database (National Consortium for the Study of Terrorism and Responses to Terrorism, 2016a) in searching for lone wolves' cases. From the Global Terrorist Database (GTD), we selected cases marked as 'Unaffiliated Individual(s)' in variable Perpetrator Group Name (gname). According to the GTD Codebook (National Consortium for the Study of Terrorism and Responses to Terrorism, 2016b), the 'Unaffiliated Individual(s)' is 'an individual who is not affiliated to a perpetrator group', which is consistent with the definition of a lone wolf. Nevertheless, as is declared in the Codebook, the practice of marking 'Unaffiliated Individual(s)' is inconsistent prior to 1998. From these reasons, only the cases since 1998 were included in the LWD. After identification of 253 suitable cases of terrorist attacks in the GTD, each case was checked manually from internet sources especially bbc.com, cnn.com, dailymail.co.uk, abcnews.go.com and foxnews.com. Unfortunately, in some countries the laws do not allow the publication of full names of convicts, which led to a substantial reduction in the sample size. Based on these sources, a total of 93 lone wolves, who committed 108 terrorist attacks were identified, i.e. their full names were given. For each identified lone wolf, we recorded variables related to the aforementioned factors, e.g. their mental state, family background, mechanism of their radicalization etc. (for detail see Table 1). Unfortunately, it was not possible to trace all the data for all persons. Therefore, the number of observations for individual variables vary from 23 to 84 observations depending on the availability of data.

Table 1. Review of assessed variables

\begin{tabular}{cccc}
\hline Factor & Abbreviation & Variable & Variants \\
\hline Individual & A1 & criminal past & yes $\mid$ no \\
& A2 & drug abuse & yes $\mid$ no \\
& A3 & mental disease diagnosed before first attack & yes $\mid$ no \\
A4 & mental disease diagnosed during trial & yes $\mid$ no \\
A5 & socially excluded person & yes $\mid$ no \\
Ideological & B1 & radical views before first attack & yes $\mid$ no \\
& B2 & ideology, religion & islam $\mid$ right wing $\mid$ left wing $\mid$ others \\
& C1 & education & basic $\mid$ lower secondary $\mid$ upper secondary $\mid$ tertiary \\
C2 & marital status before first attack & single $\mid$ in relationship $\mid$ married $\mid$ divorced $\mid$ widowed \\
& C3 & number of children & orphan $\mid$ single-parent family | two-parent family \\
& C4 & family background & yes $\mid$ no \\
& C5 & socially excluded family origin & yes $\mid$ no \\
C6 & member of minority & yes $\mid$ no \\
\hline
\end{tabular}

During statistical analysis, the frequencies were computed for the variants whose frequency exceeded $5 \%$. Variants with frequencies less than 5\% were merged into 'other' categories. Then, the association between the variables used was assessed using Spearman's rank correlation coefficient. Before the correlation coefficients were calculated, nominal variables with more than two variants were dichotomized by merging all the variants except for the variant with the highest frequency. 


\section{Results and Discussion}

Based on variant frequencies of observed variables, a preliminary profile of a lone wolf terrorist may be indicated. The vast majority (97\%) of our sample was men. There were only three women, Roshonara Choudhry, Kathryn Schoonover and Shannon Richardson. Most from our sample were aged 20-30 years at the time of their first terrorist attack (Figure 1). A notable exception is the case of James von Brunn, a senile Holocaust denier, who was 88 at the time of his attack in the United States Holocaust Memorial Museum.

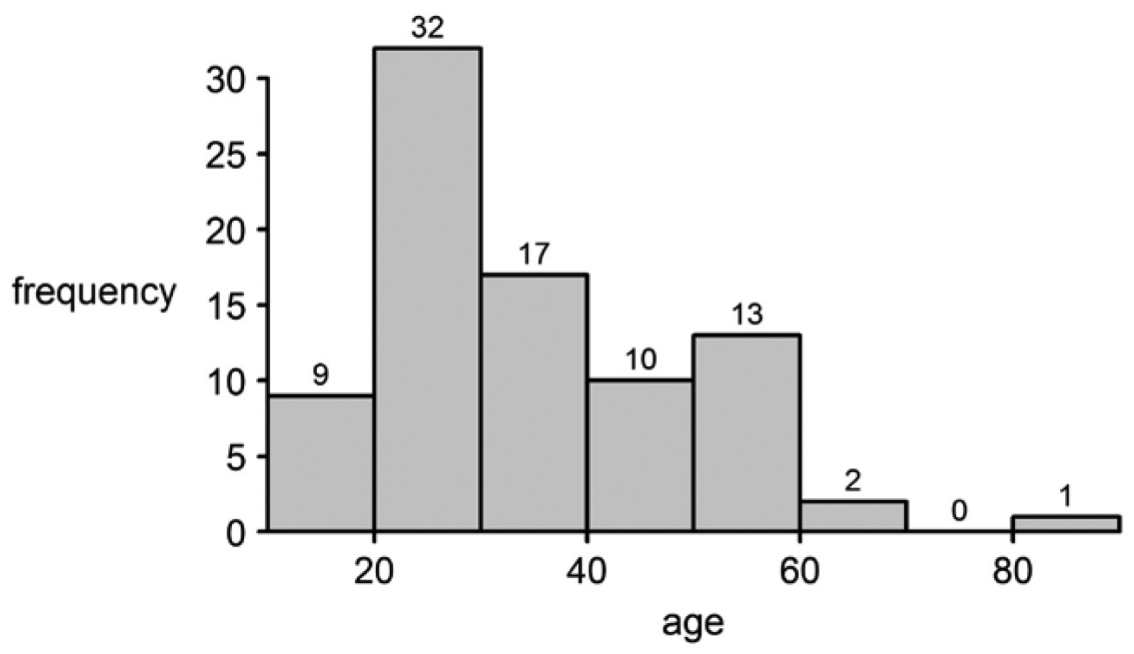

Figure 1. Age of first terrorist activity for lone wolves in our sample

Regarding the individual factor, only a limited number of lone wolves in our sample were truly socially isolated (24\%, see Figure 2). This is in contrast with the findings of Gill et al. (2014), who observed more than half of socially isolated lone wolves in their sample. However, the assessment of the social isolation of lone wolves is always subjective to a certain extent, which significantly reduces the credibility of this variable. A much reliable information is the history of criminal acts committed by wolves prior to their first terrorist attack. More than half (58\%) of our sample had a criminal past, which is consistent with the findings of Gill et al. (2014). The criminal offenses included mostly robbery, burglary, arson, weapons charges, violent activity and extortion. On the other hand, only a minority of them was a substance user in the past (19\%).

Based on available data, the presence of some mental disorder appears to be a distinctive feature for lone wolves. In nearly half (43\%) of lone wolves, some kind of mental disease was diagnosed before committing the first terrorist attack. This is an even higher number than $31 \%$ of lone wolves with a history of mental illness observed by Gill et al. (2014). Moreover, in our sample, another 13\% of lone wolves without a history of mental illness were diagnosed with a mental disease during the trial, i.e. after the terrorist act was committed.

Regarding the ideological factor, 55\% of lone wolves in our sample expressed radical views before their first attack (Figure 3). These include especially extreme Islamic views (76\%) and right wing extremism (18\%). As noticed by Ellis et al. (2016), there is significant difference in method of radical views expression. Meanwhile religiously inspired lone wolves tend to express their opinions or indicators of future attack to their friends and family members, right-wing lone wolf terrorists are more likely to use interaction on online social media. 


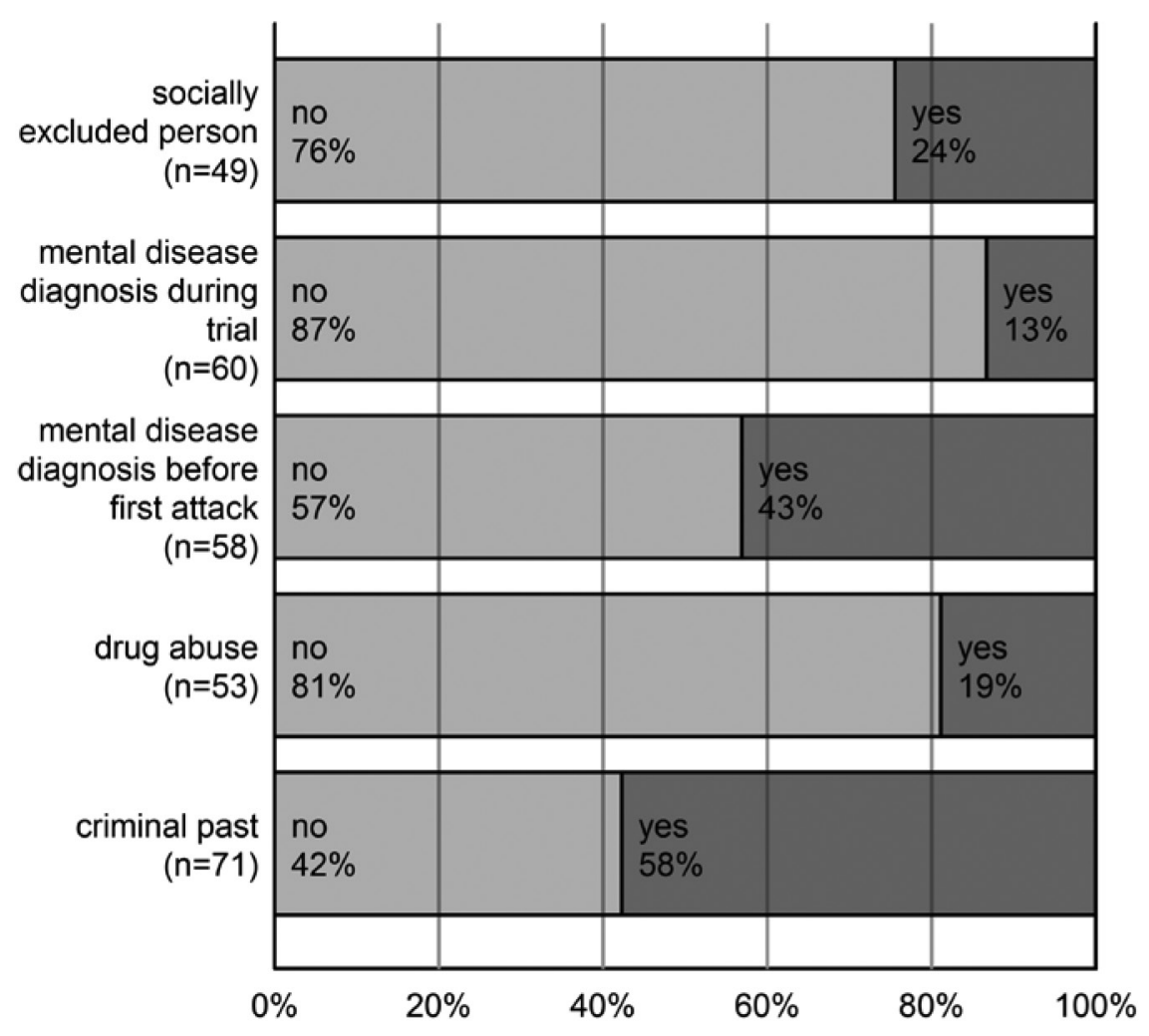

Figure 2. Frequencies of individual factor levels in our sample

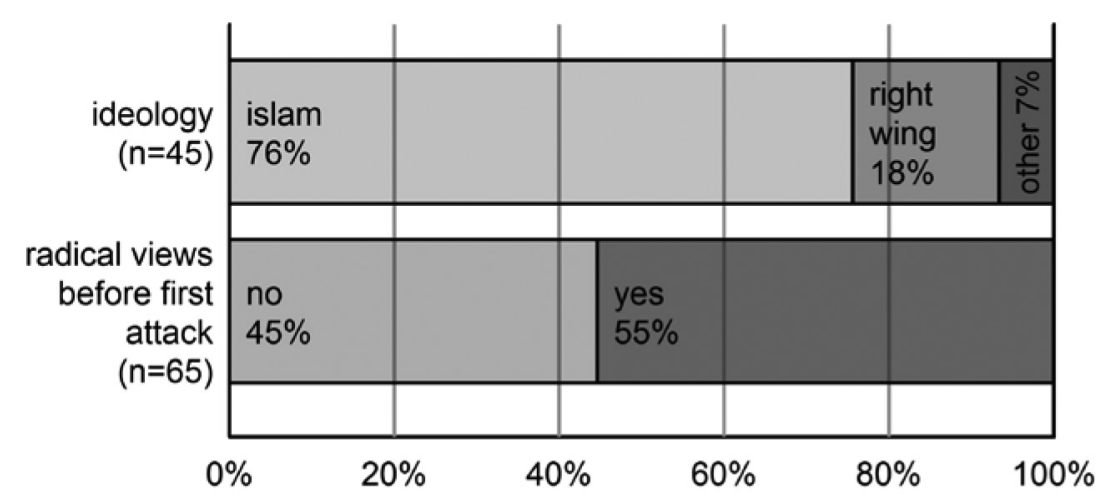

Figure 3. Frequencies of ideological factor levels in our sample

Regarding the environmental factor, almost half (45\%) of lone wolves in our sample were in no relationship and were never married, $22 \%$ of them were divorced or separated from their spouse after a previous relationship (Figure 4). This is in accordance with the findings of Gill et al. (2014). This result apparently relates to the fact that lone wolves have a relatively low number of children; most of them have no children (57\%) and only $20 \%$ have more than one children. In $52 \%$ of cases, lone wolves from our database were members of some minority group (e.g. immigrants from the Middle East, Asia and Africa) in the country, where they lived at the time of committing their terrorist attacks. On the other hand, the low-income family origin of lone wolves was relatively rare (18\%) in our sample. Likewise, the number of lone wolves coming from incomplete families $(30 \%)$ or being orphans $(3 \%)$ did not markedly deviate from the values for the common population. 


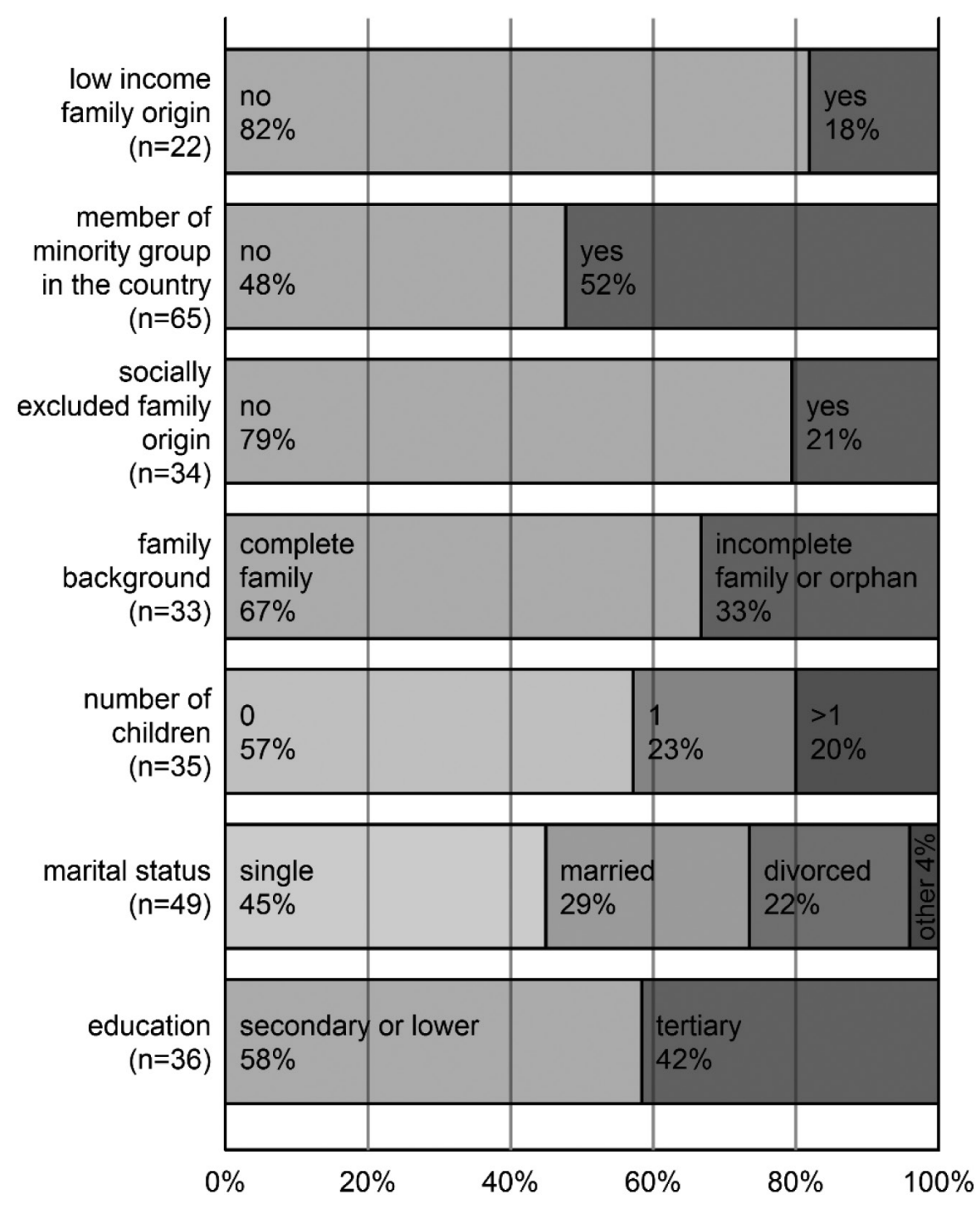

Figure 4. Frequencies of environmental factor levels in our sample

Based on the aforementioned results, it would seem that a typical lone wolf is a male member of a minority group with a criminal past, childless, lives alone, although not necessarily in social isolation, and suffers from some kind of mental disease. However, no lone wolf with all of these characteristics was really observed in our sample. Results of the performed correlation analysis also contradict such a profile of a lone wolf. As seen in Figure 5, the structure of our sample is much more complex. Based on the correlation matrix analysis and traits frequencies (Figure 2-4), four main traits of lone wolf terrorists were identified: criminal past, mental disease diagnosis before first attack, expression of radical views before first attack and minority group origin. While the last two characteristics are moderately correlated $(\mathrm{R}=0.56, \mathrm{p}<0.01)$, there were no other statistically significant correlations between these traits. In fact, a weak negative correlation was found between mental disorder diagnosis and minority group origin $(R=-0.24, \mathrm{n}$. s.). This supports the assumption that lone wolf terrorists are not a homogenous group. 


\begin{tabular}{|c|c|c|c|c|c|c|c|c|c|c|c|c|c|c|c|}
\hline & age & A1 & $\mathrm{A} 2$ & A3 & A4 & A5 & B1 & $B 2^{a}$ & $C 1^{b}$ & $\mathrm{C} 2^{\mathrm{C}}$ & C3 & $C 4^{d}$ & C5 & C6 & C7 \\
\hline age & & 0.2 & -0.07 & 0.08 & 0.13 & -0.14 & $-0.32^{*}$ & -0.27 & 0.18 & $-0.66^{\star *}$ & $0.66^{* *}$ & -0.16 & 0.19 & $-0.4^{* *}$ & -0.19 \\
\hline $\mathrm{A} 1$ & 0.2 & & $0.31^{*}$ & 0.1 & -0.24 & 0.15 & 0.25 & -0.14 & -0.09 & -0.14 & -0.02 & 0.05 & -0.01 & -0.04 & 0.09 \\
\hline A2 & -0.07 & $0.31^{*}$ & & 0.09 & -0.17 & -0.01 & 0.05 & -0.13 & -0.04 & 0.07 & -0.25 & -0.37 & -0.06 & -0.06 & -0.29 \\
\hline A3 & 0.08 & 0.1 & 0.09 & & -0.18 & $0.52^{* *}$ & 0 & 0.03 & -0.08 & 0.22 & -0.08 & -0.09 & 0.12 & -0.24 & -0.11 \\
\hline A4 & 0.13 & -0.24 & -0.17 & -0.18 & & -0.2 & $-0.36^{\star *}$ & $-0.44^{\star}$ & -0.08 & -0.23 & 0.1 & 0.01 & 0.04 & -0.25 & -0.19 \\
\hline A5 & -0.14 & 0.15 & -0.01 & $0.52^{* \star}$ & -0.2 & & 0.27 & 0.14 & $-0.37^{\star}$ & $0.4^{*}$ & \begin{tabular}{|l|l|} 
\\
\end{tabular} & 0.02 & -0.04 & 0.02 & 0.23 \\
\hline B1 & $-0.32^{*}$ & 0.25 & 0.05 & 0 & $-0.36^{* *}$ & 0.27 & & $0.54^{* *}$ & -0.12 & 0.29 & -0.32 & 0.02 & -0.12 & $0.56^{* *}$ & 0.04 \\
\hline $\mathrm{B} 2^{\mathrm{a}}$ & -0.27 & -0.14 & -0.13 & 0.03 & $-0.44^{*}$ & 0.14 & $0.54^{* *}$ & & -0.01 & 0.16 & -0.48 & 0.07 & -0.3 & $0.84^{* *}$ & 0.29 \\
\hline$C 1^{b}$ & 0.18 & -0.09 & -0.04 & -0.08 & -0.08 & $-0.37^{*}$ & -0.12 & -0.01 & & 0 & 0.32 & -0.33 & -0.14 & 0.02 & -0.27 \\
\hline $\mathrm{C} 2^{\mathrm{C}}$ & $-0.66^{* *}$ & -0.14 & 0.07 & 0.22 & -0.23 & $0.4^{*}$ & 0.29 & 0.16 & 0 & & $-0.87^{* *}$ & -0.15 & -0.33 & 0.28 & 0.18 \\
\hline C3 & $0.66^{* *}$ & -0.02 & -0.25 & -0.08 & 0.1 & $-0.41^{*}$ & -0.32 & -0.48 & 0.32 & $-0.87^{\star *}$ & & 0.37 & $0.43^{\star}$ & -0.25 & -0.06 \\
\hline$C 4^{d}$ & -0.16 & 0.05 & -0.37 & -0.09 & 0.01 & 0.02 & 0.02 & 0.07 & -0.33 & -0.15 & 0.37 & & 0.11 & -0.02 & $0.47^{*}$ \\
\hline C5 & 0.19 & -0.01 & -0.06 & 0.12 & 0.04 & -0.04 & -0.12 & -0.3 & -0.14 & -0.33 & $0.43^{*}$ & 0.11 & & -0.21 & 0.28 \\
\hline C6 & $-0.4^{* \star}$ & -0.04 & -0.06 & -0.24 & -0.25 & 0.02 & $0.56^{* \star}$ & $0.84^{* *}$ & 0.02 & 0.28 & -0.25 & -0.02 & -0.21 & & 0.12 \\
\hline C7 & \begin{tabular}{|l|}
-0.19 \\
\end{tabular} & 0.09 & -0.29 & -0.11 & -0.19 & 0.23 & 0.04 & 0.29 & -0.27 & 0.18 & -0.06 & $0.47^{*}$ & 0.28 & 0.12 & \\
\hline
\end{tabular}

Figure 4. Correlation matrix of chosen variables based on pairwise Spearman's rank correlation coefficient (variables abbreviations listed in Table 1)

For further analysis, only the individuals with no missing value in the variables corresponding with identified main traits were selected. This reduced sample consists of 43 observations. Table 2 presents some details about the distribution of the aforementioned main characteristics in the reduced sample. As seen in Table 2, only $11.6 \%$ of lone wolves in the reduced sample do not have any of the four main characteristics. On the other hand, only $7 \%$ of them has a combination of all four traits.

Table 2. Relative frequencies of criminal past (CP), mental disorder (MD), expression of radical views before first attack (RW) and minority group origin (MGO) in 43 lone wolves from our sample with no missing value in these variables

\begin{tabular}{cc}
\hline Combination of traits & Observed frequency \\
RW \& MGO & $16.3 \%$ \\
CP, RW \& MGO & $14 \%$ \\
none of given traits & $11.6 \%$ \\
MD & $9.3 \%$ \\
CP, MD \& RW & $9.3 \%$ \\
MD, RW \& MGO & $7 \%$ \\
CP & $7 \%$ \\
CP, MD, RW \& MGO & $7 \%$ \\
M \& \& RW & $4.7 \%$ \\
CP \& MD & $4.7 \%$ \\
MD \& RW & $4.7 \%$ \\
CP \& MGO & $2.3 \%$ \\
\hline
\end{tabular}

Based on these results, three overlapping groups of lone wolves could be delimited. These three categories cover a significant majority of lone wolves in our database. In fact, $83.9 \%$ of terrorists in the reduced sample can be included in at least one of these categories:

1) Lone wolves coming from a minority group expressing their radical views: 
This group represents almost half of the reduced sample (44.2\%). In Figure 5, it can be seen that lone wolves from a minority group tends to express their radical views $(\mathrm{R}=0.56, \mathrm{p}<0.01)$, predominantly adopting radical Islamic ideology $(\mathrm{R}=0.84, \mathrm{p}<0.01)$. This corresponds with the fact that these terrorists originate mostly in Muslim Diasporas in western countries. Moderate negative correlation of age at the time of first attack with minority group origin $(\mathrm{R}=-0.4, \mathrm{p}<0.01)$ testify that lone wolves from this group are usually young persons. They may have a mental disorder or criminal past, although it is not typical for them. As seen in Table 2, 31.6\% of them had a criminal past, $15.8 \%$ a mental disease diagnosis prior to their first attack and $15.8 \%$ had both of these traits. A good example of a lone wolf from this category is Dzhokhar Tsarnaev, a young immigrant to the USA who was only 19 at the time when he and his older brother Tamerlan committed the bombing attack at Boston Marathon on April 15, 2013.

The lone wolves from this group are tough to detect due to the relatively low portion of individuals with a criminal past or mental disease diagnosis. However, they are usually young and tend to express their radical views to their surroundings. As was noticed by Ellis et al. (2016), 46\% of perpetrators in the CLAT database exhibit some kind of indication of their extreme views or intentions towards others. From these cases, $35 \%$ of lone wolves exhibit only their radical ideology, $44 \%$ express also their intention to commit a terrorist attack and in $21 \%$ shared, even some details about the planned attack. As reported by Ellis et al., lone wolves usually leak the information to their friends and family members or post their opinions on the Internet. This fact possibly provides an opportunity to security forces for early detection and prevent of terrorist attacks committed by lone wolves from this group. One possibility is to convince the public about the need to notice these leakages and report them to the police. Another possibility for taking advantage of this weakness of a lone wolf terrorist lies in the development of automated or semi-automated methods for searching for and identifying radical users on the Internet, such as the method of Scrivens et al. (2017). Given the fact that religiously inspired lone wolves communicate their racial views or indicate their future actions mainly to their friends and family member (Ellis et al., 2016b), the effort should be primary focused on creating strong link and building confidence between the community and the police as suggested by Ellis and Pantucci in their Practical guidance for security practitioners (Ellis and Pantucci, 2016a).

\section{2) Lone wolves with a criminal past:}

They constitute $48.8 \%$ of the reduced sample. This finding is consistent with the results of Gill et al. (2014), who reported $41.2 \%$ of lone wolves had previous criminal convictions. They also gave some interesting details: $63.3 \%$ of lone wolves with a criminal history spent some time in jail and $32.3 \%$ of them were radicalized during incarceration. Based on the correlation matrix (Figure 5), they may tend to express their radical views before their first terrorist attack $(\mathrm{R}=0.25, \mathrm{n}$. s. $)$, although it is far from being the rule. In contrast to the previous group, they adopt various ideologies, not inclining to radical Islamic ideology exclusively. As seen in Table $2,33.3 \%$ of them had a minority group origin, $28.6 \%$ a mental disease diagnosis prior to their first attack and $14.3 \%$ had both of these characteristics. An example of a lone wolf this group be Jerad Miller: he with his wife Amanda shot three people on June 8, 2014 in Las Vegas. Miller has a rich criminal history including shoplifting, harassing telephone calls and drug offences.

Lone wolves from this group are very difficult to detect due to their relatively weak tendency of expressing their radical views. On the other hand, almost a third of them go through radicalization during their incarceration (Gill et al., 2014), where they are under surveillance and their radicalization could be potentially detected. This, however, would require the carrying out of systematic training of prison staff to increase their ability to detect signs of radicalization in prisoners.

3) Lone wolves with a mental disease diagnosed before their first terrorist attack:

They constitute $39.5 \%$ of the reduced sample. Based on the correlation matrix (Figure 5), they are more frequently socially excluded than other categories of lone wolves $(R=0.52, p<0.01)$. They may tend to live single without previous marriage $(\mathrm{R}=0.22$, n. s.). On the other hand, there was no observed tendency for 
expression of their radical views before the attack $(R=0.00, n$. s.). As seen in Table $2,17.7 \%$ of them had a minority group origin and $35.3 \%$ a criminal past and $17.7 \%$ had both of these traits. An example of a lone wolf from this category is Scott Philip Roeder, an anti-abortion militant who shot George Tiller, a well-known doctor in the US who performed late-term abortions, on May 31, 2009. Long before carrying out the attacks, Roeder was diagnosed with possible schizophrenia, however, functioned without medication and medical surveillance. As noted by Ellis et al. (2016a), among lone wolves that have used legally-owned firearms for their attacks, 53 $\%$ of them have an indication of some mental health disorder.

Lone wolves with mental illness constitute a very interesting group. Due to the fact, that these people have undergone some kind of mental health examination at some point during their lives, there could be a higher possibility of their timely detection or monitoring. On the other hand, in most cases, the mental health examination constitutes the only opportunity for their timely detection. As seen in Figure 5, mental illness diagnosis before a terrorist attack is strongly and statistically highly significantly correlated with the social isolation of the perpetrator $(\mathrm{R}=0.52, \mathrm{p}<0.01)$. It should be taken into consideration however, that this finding differs from the result of Corner and Gill (2015), who failed to find any statistically significant association between mental illness and social isolation in lone wolves. In addition to the tendency for social isolation, lone wolves with mental illness tend to express their radical views less than others. Based on Table 2, only $50 \%$ of lone wolves from the reduced sample with a mental illness and no criminal past expressed radical views before their attacks. Moreover, in accordance with Corner and Gill, no statistically significant correlation between a criminal past and mental illness was found. In the study by Corner and Gill, schizophrenia and associated disorders were the only mental health disturbances associated with acts of violence performed prior to the first terrorist attack. As highlighted by Ellis and Pantucci (2016a), when a future lone wolf is socially isolated, it is unlikely that anyone will recognize and report indications of his extremist behavior or his intention to perform a terrorist attack. In these cases, the mental health practitioner could be the only one person that has a chance to timely detect such a lone wolf terrorist. Corner and Gill (2015) came up with another important piece of information. They found out that lone wolves with mental illness have a significantly higher likelihood of having a spouse or partner associated with a wider movement. They suggested that lone wolves with mental illness may be susceptible to ideological influences from their surroundings.

Recently, Bakker and Zuijdewijn (2016) published a Practical guidance for mental health practitioners and social workers, where they recommended the introduction of measures for wider availability of mental health services, as well as enhancing information-sharing between mental health practitioners and law enforcement, which is also supported by other authors (Chermak et al., 2010; Corner and Gill, 2015; Zuijdewijn and Bakker, 2016). On the other hand, they advise against hotlines where people can report suspicious behavior in persons in their neighborhood, because the high number of expected false positive reports made by non-professionals. Another interesting suggestion by Bakker and Zuijdewijn is their recommendation to prepare anonymized biographies of lone wolves that could be utilized as training materials for relevant actors.

In his critique of research on terrorism, Silke (2001) sees one of the most important methodological issue of published studies in the fact, that a large portion of these studies use secondary data, especially scholarly books and articles, media news services and open government documents. They review all articles and research records published between 1995 and 1999 in two of the most important terrorism studies journals: Terrorism and Political Violence and Studies in Conflict \& Terrorism. They discovered that $73 \%$ of published studies in this period are based solely or predominantly on documentary analysis or review. He identified three possible issues connected with secondary data, especially from media sources: 1) questionable accuracy of information presented by the media; 2) biases caused by the non-neutrality of some media reports and 3) misinterpretation of media reports caused by the fact that the reports are not written in scientific language, but are intended for a specific audience.

It should be highlighted that our data are based solely on open sources and as such are subject to the aforementioned issues. The first problem of the data used is their incompleteness. As mentioned in the Methods section, out of 253 terrorist attacks documented in GTD, additional information was found only for 108 terrorist attacks, 
resp. 93 lone wolves. Even regarding these cases of lone wolves, there were plenty of missing values. Actually, there were only five cases of lone wolves, which did not contain any missing values in the assessed variables listed in Table 1. The critical question is why this missing information could not be found in open sources. The most probable explanation is that this information was actually unavailable to the media or was found to be uninteresting. This necessarily leads to some kind of bias, since the lone wolves who performed more dramatic and serious terrorist attacks received more attention in media. Due to this bias, the obtained results definitely cannot be compared with the population values. On the other hand, values of correlation coefficients should be unaffected by these kinds of selections. Media can also possibly influence values of observed traits by exaggerating the reality, e.g. by paying more attention to terrorists with an "interesting personal story", such as a criminal past, dysfunctional family origin etc. However, until this selection is at the level of individual traits and not their combinations, the correlations between traits should not be inflicted. Based on these assumptions, we consider the performed correlation analysis to be sufficiently reliable.

\section{Conclusions}

Based on the results of our study, it can be said that lone wolf terrorists in western countries are not part of a homogenous group. It is not possible to categorize and summarize the issue of lone wolves unequivocally. Each actor of this kind is specific in terms of his or her personality, behavior and reasons. In general, however, three main groups of lone wolves were identified: 1) young lone wolves coming from a minority, 2) lone wolves with a criminal past and 3) lone wolves with a mental disease. State security forces could monitor such defined groups of persons under certain conditions within the crisis management system. Closer monitoring of radicals with a criminal past and/or history of mental illness could reduce the risk of a terrorist attack committed by a lone wolf. Regarding young lone wolf terrorists from minority groups, their tendency to reveal their terrorist acts or extreme opinions to their friends or family members appears to be their most vulnerable characteristic, which can be used for their early identification. However, this process requires an active approach from the public, especially those people who are in contact with potential lone wolf terrorists. They have to be convinced of the necessity to notice the indications of future terrorist acts and to report them to the police. Besides that, they must be able to recognize these indications. This requires the transmission of relevant information to the public. Studying the common characteristics of lone wolves could be an important part of the effort of creating a 'well-informed public'. In fact, a 'well-informed public' can play a fundamental and irreplaceable role in the fight against terrorism, particularly against lone wolves. The public could be the force that plays the necessary role of an observer, and draws attention to unusual conduct and behavior of individuals in society.

\section{Acknowledgements}

The first two authors were supported by the Ministry of Education, Youth and Sports of the Czech Republic (research project SV18-FVL-K106-BĽE).

\section{References}

Bakker, E.; de Graaf, B. 2010. Lone Wolves: How to Prevent This Phenomenon? International Centre for Counter-Terrorism - The Hague. Available on the Internet: https://www.icct.nl/download/file/ICCT-Bakker-deGraaf-EM-Paper-Lone-Wolves.pdf

Bakker, E.; van Zuijdewijn, J. de R. 2016. Lone-Actor Terrorism Toolkit Paper 1: Practical Guidance for Mental Health Practitioners and Social Workers. Countering Lone-Actor Terrorism Series No. 9. Available on the Internet: https://rusi.org/projects/lone-actor-terrorism

Berwick, A., 2011. 2083: A European Declaration of Independence.

Chermak, S. M.; Freilich, J. D.; Simone, J. 2010. Surveying American State Police Agencies About Lone Wolves, Far-Right Criminality, and Far-Right and Islamic Jihadist Criminal Collaboration. Studies in Conflict \& Terrorism 33(11): 1019-1041. DOI: https://doi.org/10. 1080/1057610X.2010.514698

Corner, E.; Gill, P. 2015. A False Dichotomy? Mental Illness and Lone-Actor Terrorism. Law and Human Behavior 39(1): 23-34. DOI: https://doi.org/10.1037/lhb0000102

Corner, E.; Gill, P.; Mason, O. 2016. Mental Health Disorders and the Terrorist: A Research Note Probing Selection Effects and Disorder Prevalence. Studies in Conflict \& Terrorism 39(6): 560-568. DOI: https://doi.org/10.1080/1057610X.2015.1120099 
Ellis, C.; Pantucci, R. 2016a. Lone-Actor Terrorism Toolkit Paper 2: Practical Guidance for Security Practitioners. Countering LoneActor Terrorism Series No. 10. Available on the Internet: https://rusi.org/projects/lone-actor-terrorism

Ellis, C.; Pantucci, R. 2016b. Lone-Actor Terrorism Policy Paper 4: 'Leakage' and Interaction with Authorities. Countering Lone-Actor Terrorism Series No. 8. Available on the Internet: https://rusi.org/projects/lone-actor-terrorism

Ellis, C.; Pantucci, R.; van Zuijdewijn, J. de R.; Bakker, E.; Gomis, B.; Palombi, S.; Smith, M. 2016a. Lone-Actor Terrorism Analysis Paper. Countering Lone-Actor Terrorism Series No. 4. Available on the Internet: https://rusi.org/projects/lone-actor-terrorism

Ellis, C.; Pantucci, R.; van Zuijdewijn, J. de R.; Bakker, E.; Gomis, B.; Palombi, S.; Smith, M. 2016b. Lone-Actor Terrorism Final Report. Countering Lone-Actor Terrorism Series No. 11. Available on the Internet: https://rusi.org/projects/lone-actor-terrorism

Gill, P.; Horgan, J.; Deckert, P. 2014. Bombing Alone: Tracing the Motivations and Antecedent Behaviors of Lone-Actor Terrorists. Journal of Forensic Sciences 59(2): 425-435. DOI: https://doi.org/10.1111/1556-4029.12312

Gruenewald, J.; Chermak, S.; Freilich, J. D. 2013. Distinguishing "Loner" Attacks from Other Domestic Extremist Violence: A Comparison of Far-Right Homicide Incident and Offender Characteristics. Criminology and Public Policy 12(1): 65-91. DOI: https:// doi.org/10.1111/1745-9133.12008

Hamm, M.; Spaaij, R. 2015. Lone Wolf Terrorism in America: Using Knowledge of Radicalization Pathways to Forge Prevention Strategies. Available on the Internet: https:/www.ncjrs.gov/pdffiles1/nij/grants/248691.pdf

Holt, T.; Freilich, J. D.; Chermak, S.; McCauley, C. 2015. Political radicalization on the Internet: Extremist content, government control, and the power of victim and jihad videos. Dynamics of Asymmetric Conflict 8(2): 107-120. DOI: https://doi.org/10.1080/17467586.201 5.1065101

Joosse, P. 2017. Leaderless Resistance and the Loneliness of Lone Wolves: Exploring the Rhetorical Dynamics of Lone Actor Violence. Terrorism and Political Violence 29(1): 52-78. DOI: https://doi.org/10.1080/09546553.2014.987866

Kemmesies, U. E. 2006. Zukunftsaussagen wagen: Zwischen Verstehen und Erklä_ren - Methodologische und theoretische Notizen zur Prognoseforschung im Phä_nomenbereich Extremismus/Terrorismus., in Kemmesies, U. E. (Ed.). Terrorismus Und Extremismus - Der Zukunft Auf Der Spur. Luchterhand, 1-39.

Khalil, J. 2014. Radical Beliefs and Violent Actions Are Not Synonymous: How to Place the Key Disjuncture Between Attitudes and Behaviors at the Heart of Our Research into Political Violence. Studies in Conflict \& Terrorism 37(2): 198-211. DOI: https://doi.org/10. 1080/1057610X.2014.862902

Kuril, J. 2018. Public administration for safe and secure environment: case of Slovak Republic, Entrepreneurship and Sustainability Issues 5(3): 493-501. https://doi.org/10.9770/jesi.2018.5.3(6)

Lietuvnikè, M. M.; Vasilis Vasiliauskas, A.; Vasilienè-Vasiliauskienė, V.; Sabaitytė, J. 2018. Peculiarities of illegal immigrant's intrusions into road freight transport units in the France - UK corridor, Entrepreneurship and Sustainability Issues 5(3): 634-647. https://doi. org/10.9770/jesi.2018.5.3(16)

Lincényi, M. 2017. Entrepreneurship ecosystem facets: the European migrant crisis and public opinion in Slovakia, Entrepreneurship and Sustainability Issues 5(2): 357-367. https://doi.org/10.9770/jesi.2017.5.2(14)

McCauley, C.; Moskalenko, S. 2008. Mechanisms of Political Radicalization: Pathways Toward Terrorism. Terrorism and Political Violence 20(3): 415-433. DOI: https://doi.org/10.1080/09546550802073367

McCauley, C.; Moskalenko, S. 2014. Toward a Profile of Lone Wolf Terrorists: What Moves an Individual From Radical Opinion to Radical Action. Terrorism and Political Violence 26: 69-85. DOI: https://doi.org/10.1080/09546553.2014.849916

Moskalenko, S., McCauley, C., 2011. The psychology of lone-wolf terrorism. Counselling Psychology Quarterly 24(2): 115-126. DOI: https://doi.org/10.1080/09515070.2011.581835

National Consortium for the Study of Terrorism and Responses to Terrorism 2016a. Global Terrorism Database [Data file]. Available on the Internet: https://www.start.umd.edu/gtd

National Consortium for the Study of Terrorism and Responses to Terrorism 2016b. Global Terrorism Database Codebook: Inclusion Criteria and Variables. Available on the Internet: https://www.start.umd.edu/gtd

Pantucci, R.; Ellis, C.; Chaplais, L. 2015. Lone-Actor Terrorism Literature Review. Countering Lone-Actor Terrorism Series No. 1. Available on the Internet: https://rusi.org/projects/lone-actor-terrorism 
Schuurman, B.; Eijkman, Q. 2015. Indicators of terrorist intent and capability: Tools for threat assessment. Dynamics of Asymmetric Conflict 8(3): 215-231. DOI: https://doi.org/10.1080/17467586.2015.1040426

Scrivens, R.; Davies, G.; Frank, R. 2017. Searching for signs of extremism on the web: an introduction to Sentiment-based Identification of Radical Authors. Behavioral Sciences of Terrorism and Political Aggression 10(1): 39-59. DOI: https://doi.org/10.1080/19434472.2 016.1276612

Silke, A. 2001. The Devil You Know: Continuing Problems with Research on Terrorism. Research on Terrorism: Trends, Achievements and Failures 13(4): 1-14. DOI: https://doi.org/10.4324/9780203500972

Šišulák, S. 2017. Userfocus - tool for criminality control of social networks at both the local and international level, Entrepreneurship and Sustainability Issues 5(2): 297-314. https://doi.org/10.9770/jesi.2017.5.2(10)

Spaaij, R. 2010. The Enigma of Lone Wolf Terrorism: An Assessment. Studies in Conflict \& Terrorism 33(9): 854-870. DOI: https://doi. org/10.1080/1057610X.2010.501426

Spaaij, R. 2012. Understanding Lone Wolf Terrorism Global Patterns, Motivations and Prevention. Dordecht: Published by Springer. DOI: https://doi.org/10.1007/978-94-007-2981-0

Todorov, G. N.; Kalinina, A. V.; Rybakova, A. I. 2018. Impact of labour migration on entrepreneurship ecosystem: case of Eurasian Economic Union, Entrepreneurship and Sustainability Issues 5(4): 992-1007. https://doi.org/10.9770/jesi.2018.5.4(20)

van Zuijdewijn, J. de R.; Bakker, E. 2016. Lone-Actor Terrorism Policy Paper 1: Personal Characteristics of Lone-Actor Terrorists. Countering Lone-Actor Terrorism Series No. 5. Available on the Internet: https://rusi.org/projects/lone-actor-terrorism

Victoroff, J. 2005. The Mind of the Terrorist: A Review and Critique of Psychological Approaches. Journal of Conflict Resolution 49(1): 3-42. DOI: https://doi.org/10.1177/0022002704272040

World Health Organization 2010. International Statistical Classification of Diseases and Related Health Problems 10th Revision. Available on the Internet: http://apps.who.int/classifications/icd10/browse/2016/en

Zeman, T.; Břeň, J.; Urban, R. 2017. Role of Internet in Lone Wolf Terrorism, Journal of Security and Sustainability Issues 7(2): 185-192. https://doi.org/10.9770/jssi.2017.7.2(1)

\section{Tomáš Zeman}

ORCID ID: orcid.org/0000-0001-7269-4994

\section{Jan Břeň}

ORCID ID: orcid.org/0000-0003-1565-4050

\section{Rudolf Urban}

ORCID ID: orcid.org/0000-0003-1893-4648 